\title{
Pengaruh senam bugar lansia terhadap kebugaran jantung paru di Panti Werdha Bethania Lembean
}

\author{
${ }^{1}$ George Lengkong \\ ${ }^{2}$ Sylvia R. Marunduh \\ ${ }^{2}$ Herlina I. S. Wungow \\ ${ }^{1}$ Kandidat Skripsi Fakultas Kedokteran Universitas Sam Ratulangi Manado
${ }^{2}$ Bagian Fisiologi Fakultas Kedokteran Universitas Sam Ratulangi Manado
Email: georgelengkong@gmail.com
}

\begin{abstract}
A person's physical well-being is one of the indicators of quality of life. Elderly who have good life quality are expected to have good physical well-being. Physical changes occur during aging process. After 30 years old the cardiorespiratory fitness begins to decrease. One measurement that is most used to determine the level of cardiorespiratory fitness is the maximum oxygen consumption $\left(\mathrm{VO}_{2} \mathrm{max}\right)$. This study was aimed to determine the effect of elderly fitness exercise to cardiorespiratory fitness among elderly at Panti Werdha Bethania Lembean (senior housing) with $\mathrm{VO}_{2} \max$ as the measurement. This was a field experimental study with a pre-post one group test design. There were 15 subjects who met the inclusion criteria consisted of 5 males and 10 females. Subjects were selected by using purposive sampling method. The cardiorespiratory fitness level was measured by using $\mathrm{VO}_{2}$ max, with 6minute walk test. The results showed that the average of $\mathrm{VO}_{2} \max$ before exercise was 6.73 $\mathrm{ml} / \mathrm{kg} / \mathrm{minute}$, while the average of $\mathrm{VO}_{2}$ max after exercise was $6.78 \mathrm{ml} / \mathrm{kg} / \mathrm{minute}$. The data were analyzed by using paired sample t-test $(p=0.035)$. Conclusion: The elderly fit fitness had a significant effect on cardiorespiratory fitness.
\end{abstract}

Keywords: elderly, exercise, $\mathrm{VO}_{2} \max$

\begin{abstract}
Abstark: Kesejahteraan fisik seseorang merupakan salah satu indikator kualitas hidup. Lansia yang memiliki kualitas hidup baik secara tidak langsung memiliki kesejahteraan fisik yang baik pula. Pada proses penuaan terjadi perubahan fisik. Setelah mencapai usia 30 tahun terjadi penurunan kebugaran jantung paru sebesar $1 \%$ setiap tahun. Salah satu tolak ukur yang paling sering digunakan untuk mengetahui tingkat kebugaran jantung paru ialah konsumsi oksigen maksimum $\left(\mathrm{VO}_{2}\right.$ maks). Penelitian ini bertujuan untuk mengetahui pengaruh senam bugar lansia terhadap kebugaran jantung paru di Panti Werdha Bethania Lembean dengan tolak ukur $\mathrm{VO}_{2}$ max. Jenis penelitian ini ialah eksperimental lapangan dengan desain pre-post one group test. Subyek yang memenuhi kriteria inklusi terdiri dari 15 orang dengan 5 orang laki-laki dan 10 orang perempuan dipilih dengan purposive sampling. Tingkat kebugaran jantung paru dilakukan dengan pengukuran $\mathrm{VO}_{2}$ maks, diukur dengan uji jalan 6 menit. Hasil penelitian memperlihatkan rerata $\mathrm{VO}_{2}$ maks sebelum program latihan senam bugar lansia 6,73 $\mathrm{ml} / \mathrm{kg} / \mathrm{menit}$ sedangkan setelah program latihan senam bugar lansia didapatkan 6,78 $\mathrm{ml} / \mathrm{kg} / \mathrm{menit}$. Hasil uji t berpasangan didapatkan $\mathrm{p}=0,035$. Simpulan: Senam bugar lansia memiliki pengaruh bermakna terhadap kebugaran jantung paru.
\end{abstract}

Kata kunci: lansia, senam, $\mathrm{VO}_{2}$ maks

Salah satu indikator keberhasilan pembangunan ialah semakin meningkatnya usia harapan hidup penduduk. Dengan meningkatnya usia harapan hidup penduduk menyebabkan jumlah penduduk lanjut usia terus meningkat dari tahun ke 
tahun. ${ }^{1}$ Berdasarkan definisi secara umum di katakan lanjut usia (lansia) apabila usianya 60 tahun ke atas. Lansia bukan merupakan suatu penyakit namun merupakan tahap lanjut dari suatu proses kehidupan yang ditandai dengan penurunan kemampuan tubuh untuk berdaptasi dengan stress lingkungan. ${ }^{2}$

Kualitas hidup lansia merupakan salah satu indikator yang digunakan untuk mengukur tingkat keberhasilan seorang lansia menjalani masa tuanya. Kualitas hidup memperlihatkan keadaan emosional, sosial dan kesejahteraan fisik seseorang, juga kemampuannya untuk berfungsi dalam kehidupan sehari-hari. Lansia yang memiliki kualitas hidup yang baik secara tidak langsung memiliki kemampuan untuk melakukan berbagai aktivitas fisik, mampu mengadakan interaksi sosial dengan baik, serta memiliki kondisi emosional yang stabil. $^{3}$

Penduduk lansia Indonesia menempati peringkat empat terbesar di dunia setelah China, India, dan Amerika. Pada sensus penduduk 2010 yang diselenggarakan BPS di seluruh wilayah Indonesia berjumlah 237.641.326 jiwa. Menurut keadaan kesehatan jumlah penduduk lansia di Indonesia mencapai 15.454.960 jiwa. Di Provinsi Sulawesi Utara sendiri lansia tercatat 174.077 jiwa, dengan keadaan baik sebanyak 84.718 jiwa, sedangkan 69.710 jiwa dengan keadaan cukup, dan 19.649 jiwa dengan keadaan kurang. ${ }^{4}$

Pada proses menua terjadi perrubahan fisik, mental, psikososial maupun spiritual yang cenderung mengalami kemunduran. Setelah mencapai usia 30 tahun terjadi penurunan kebugaran jantung paru $1 \%$ setiap usia bertambah satu tahun. Kebugaran jantung paru merupakan indikator pemakain oksigen oleh jantung dan paru-paru, dimana pada usia 60 tahun kebugaran jantung paru akan berkurang $35 \%$. Banyak faktor yang memengaruhi tingkat kebugaran jantung paru antara lain: keturunan, usia, jenis kelamin, gizi, merokok, dan aktivitas fisik. ${ }^{5}$

Latihan fisik sangat penting dalam membantu lansia beraktivitas. Olahraga merupakan salah satu aktifitas yang baik untuk lansia. Jenis olahraga yang bisa dilakukan pada lansia ialah senam. Senam bugar lansia adalah serangkaian gerak nada yang teratur dan terarah serta terencana yang diikuti oleh orang lanjut usia yang dilakukan dengan maksud meningkatkan kemampuan fungsional raga secara bertahap. $^{6}$

Salah satu tolak ukur yang paling sering digunakan untuk mengetahui tingkat kebugaran jantung paru ialah konsumsi oksigen maksimal $\left(\mathrm{VO}_{2} \mathrm{max}\right)$. Pada lansia penurunan kapasitas kardiorespirasi akan memengaruhi $\quad \mathrm{VO}_{2} \max . \quad \mathrm{VO}_{2} \max$ mengalami penurunan sesuai dengan bertambahnya usia. Menurut Oliveira terjadinya penurunan $\mathrm{VO}_{2} \max$ seiring bertambahnya usia dimana kecepatan penurunan $\mathrm{VO}_{2}$ max pada lansia sekitar $10 \%$ per dekade, dan $5 \%$ per dekade pada orang aktif. $^{7}$

Penelitian yang dilakukan pada tahun 2013 oleh Ni Made Parwati ${ }^{7}$ menunjukkan peningkatan $0,87 \mathrm{ml} / \mathrm{kg} /$ menit kebugaran jantung paru sebelum dan sesudah melakukan senam. Van Roei et al. ${ }^{8}$ pada tahun 2010 mendapatkan aktivitas fisik yang terprogram serta pola hidup sehat dapat memperlambat penurunan $\mathrm{VO}_{2}$ max.

Penelitian ini bertujuan untuk mengetahui pengaruh Senam Bugar Lansia terhadap kebugaran jantung paru di Panti Werdha Bethania Lembean".

\section{METODE PENELITIAN}

Jenis penelitian yang digunakan ialah eksperimental lapangan dengan desain prepost one group test.

Penelitian dilaksanakan di Panti Werdha Bethania Lembean. Populasi ialah semua lansia di Panti Werdha Bethania Lembean. Pengambilan sampel menggunakan metode purposive sampling. Tingkat kebugaran jantung paru dilakukan dengan pengukuran $\mathrm{VO}_{2}$ maks, dengan uji jalan 6 menit. Sampel yang didapat berjumlah 15 orang yang telah memenuhi kriteria inklusi dan ekslusi. 


\section{HASIL DAN BAHASAN}

Penelitian dilaksanakan dengan cara pre-post one group test selama lima minggu, dengan dilakukan perlakuan sebelum dan sesudah mengikuti program latihan senam bugar lansia. Sebelum memulai penelitian para subyek diwawancara untuk penyaringan dan kemudian wajib mengisi lembar informed consent.

Para subyek dianjurkan untuk tidak merokok selama program latihan berlangsung, mengatur pola makan, dan tidak melakukan aktifitas fisik yang berat. Dari 33 populasi yang didapat di Panti Werdha Bethania Lembean, terdapat 15 sampel yang sesuai dengan kriteria inklusi.

Berdasarkan hasil pada Tabel 1 didapatkan bahwa jumlah sampel terbanyak ialah wanita dengan persentase $66,67 \%$ sedangkan pria sebanyak $33,33 \%$.

Tabel 1. Distribusi lansia berdasarkan jenis kelamin di Panti Werdha Bethania

\begin{tabular}{ccc}
\hline Jenis kelamin & n & \% \\
\hline Pria & 5 & 33,33 \\
Wanita & 10 & 66,67 \\
Jumlah & 15 & 100,00 \\
\hline
\end{tabular}

Data Tabel 2 menunjukkan bahwa sampel terbanyak ialah lansia usia 70-79 tahun $(53,33 \%)$ sedangkan sampel dengan usia 60-69 tahun sebesar 46,67\%.

Berdasarkan Tabel 3, pada hasil uji jalan enam menit sebelum dilakukan program senam 15 sampel memiliki rata- rata jarak tempuh 91,93 meter sedangkan setelah dilakukan program senam 15 sampel memiliki rata-rata jarak tempuh sejauh 93,33 meter.

Berdasarkan Tabel 4, dari 15 sampel yang diteliti pada sebelum program latihan senam bugar lansia didapatkan nilai minimum $5,78 \mathrm{ml} / \mathrm{kg} / \mathrm{menit}$ sedangkan setelah dilakukan program latihan senam bugar lansia didapatkan $5,90 \mathrm{ml} / \mathrm{kg} /$ menit. Nilai maksimum sebelum program latihan senam bugar lansia didapatkan 7,58 $\mathrm{ml} / \mathrm{kg} /$ menit sedangkan setelah dilakukan program didapatkan $7,70 \mathrm{ml} / \mathrm{kg} /$ menit. Nilai rata-rata sebelum dilakukan program latihan senam bugar pada lansia didapatkan $6,73 \mathrm{ml} / \mathrm{kg} / \mathrm{menit}$ sedangkan setelah diberikan perlakuan didapatkan 6,78 $\mathrm{ml} / \mathrm{kg} / \mathrm{menit}$.

Tabel 2. Distribusi lansia berdasarkan usia di Panti Werdha Bethania

\begin{tabular}{ccc}
\hline Usia & $\mathbf{n}$ & $\boldsymbol{\%}$ \\
\hline $60-69$ & 7 & 46,67 \\
$70-79$ & 8 & 53,33 \\
Jumlah & 15 & 100 \\
\hline
\end{tabular}

Tabel 3. Distribusi hasil jarak six-minute walk test (6MWT) sebelum dan sesudah melakukan program senam bugar lansia di Panti Werdha Bethania

\begin{tabular}{ccc}
\hline & $\begin{array}{c}\text { Jarak } \\
\text { sebelum } \\
\text { (meter) }\end{array}$ & $\begin{array}{c}\text { Jarak } \\
\text { sesudah } \\
\text { (meter) }\end{array}$ \\
\hline Rata-rata & 91,93 & 93,33 \\
\hline
\end{tabular}

Tabel 4. Distribusi nilai deskriptif statistik $\mathrm{VO}_{2} \mathrm{Max}(\mathrm{ml} / \mathrm{kgBB} /$ menit) sebelum dan sesudah melakukan program senam bugar lansia di Panti werdha Bethania

\begin{tabular}{lccc}
\hline & $\begin{array}{c}\text { Minimum } \\
\mathbf{m l} / \mathbf{k g} / \text { menit }\end{array}$ & $\begin{array}{c}\text { Maximum } \\
\mathbf{m l} / \mathbf{k g} / \mathbf{m e n i t}\end{array}$ & $\begin{array}{c}\text { Rata-rata } \\
\mathbf{m l} / \mathbf{k g} / \mathbf{m e n i t}\end{array}$ \\
\hline $\mathbf{V O}_{2} \mathbf{m a x}$ pre & 5,78 & 7,58 & 6,73 \\
VO $_{2}$ max post & 5,90 & 7,70 & 6,78 \\
\hline
\end{tabular}

Faktor-fakor yang dapat berpengaruh terhadap nilai $\mathrm{VO}_{2}$ max antara lain: usia, jenis kelamin, keadaan latihan, fungsi paru, fungsi kardiovaskuler, sel darah merah, gaya hidup. ${ }^{9}$

Pada penelitian ini didapatkan jumlah 15 sampel dengan nilai rata-rata sebelum melakukan program latihan senam lansia 
diperoleh $6,7387 \mathrm{ml} / \mathrm{kg} / \mathrm{menit}$ dan setelah melakukan program latihan senam lansia diperoleh $6,7880 \mathrm{ml} / \mathrm{kg} / \mathrm{menit}$. Berdasarkan hasil analisis statistik dengan uji $t$ berpasangan didapatkan peningkatan nilai $\mathrm{VO}_{2}$ max secara bermakna setelah mengikuti program latihan $(\mathrm{p}=0,035)$.

Peningkatan ini dipengaruhi oleh beberapa hal yaitu: usia dan jenis kelamin, latihan fisik, fungsi kardiovaskkuler, komposisi tubuh, serta penurunan denyut jantung. ${ }^{7-9}$

Usia dan jenis kelamin sangat berpengaruh terhadap nilai $\mathrm{VO}_{2} \max$. Penelitian sebelumnya mendapatkan terjadi penurunan nilai $\mathrm{VO}_{2}$ max per tahun sebesar $0,46 \mathrm{ml} / \mathrm{kg} / \mathrm{menit}$ pada pria dan 0,54 $\mathrm{ml} / \mathrm{kg} / \mathrm{menit}$ pada wanita. Pollock et al. menyatakan pada olahragwan lansia dengan usia 50-82 tahun, periode penurunan nilai $\mathrm{VO}_{2} \max$ terjadi dalam kurun waktu 10 tahunan. Latihan fisik adalah proses mengembangkan kemampuan aktivitas gerak jasmani yang dilakukan secara sistematik serta ditingkatkan secara progresif untuk meningkatkan derajat kebugaran jasmani agar tercapai kemampuan kerja fisik yang optimal. Respons kardiovaskuler yang paling utama terhadap aktivitas fisik ialah peningkatan cardiac output. Peningkatan ini disebabkan oleh isi sekuncup jantung maupun heart rate yang dapat mencapai sekitar 95\% dari tingkat maksimalnya. Karena pemakaian oksigen tubuh tidak dapat melebihi kecepatan sistem kadiovaskuler menghantarkan oksigen ke jaringan, maka dapat dikatakan bahwa sistem kardiovaskuler dapat membatasi nilai $\mathrm{VO}_{2}$ max. ${ }^{7-9}$ Mengenai komposisi tubuh, konsumsi oksigen maksimal dinyatakan dalam beberapa milimeter oksigen yang dikonsumsi perkilogram berat badan, perbedaan komposisi tubuh seseorang menyebabkan konsumsi yang berbeda. Orang terlatih akan memiliki denyut jantung istirahat yang lebih rendah daripada yang tidak terlatih. Denyut jantung yang lebih rendah mengakibatkan nilai $\mathrm{VO}_{2} \max$ pada orang terlatih relatif lebih tinggi dibandingkan pada yang tidak terlatih. Setelah melakukan latihan fisik denyut jantung dapat mengalami penurunan selama waktu tertentu; hal ini merupakan kompensasi tubuh terhadap latihan fisik. ${ }^{7-9}$ Latihan fisik aerobik dapat meningkatkan nilai $\mathrm{VO}_{2}$ max sekitar $10-20 \%{ }^{8}$

Adanya keterbatasan waktu sehingga latihan senam pada penelitian ini hanya dapat dilakukan 1 kali seminggu selama 5 minggu sehingga peningkatan nilai $\mathrm{VO}_{2}$ max tidak maksimal. Waktu yang seharusnya dianjurkan ialah 8 minggu sampai 12 minggu agar mendapatkan hasil yang maksimal pula.

Berdasarkan hasil analisis data menggunakan paired sample T-Test, nilai $\mathrm{VO}_{2}$ max sebelum dan sesudah melakukan program latihan senam bugar lansia selama kurang lebih 4 minggu mendapatkan nilai $\mathrm{p}=0,035$ yang menunjukkan bahwa senam bugar lansia dapat meningkatkan VO2max.

\section{DAFTAR PUSTAKA}

1. Penduduk lanjut usia. Available from; http://menegpp.go.id/v2/index.php/da tadaninformasi/kependudukan?downl oad=9\%3 Apenduduk-lanjut-usia

2. Efendy F, Makhfudli. Keperawatan Kesehatan Komunitas Jilid 1. Jakarta: Salemba Medika, 2009; p. 243.

3. Hugget D. Maximal aerobic capacity testing of older adults: A critical review. J Gerontol. 2010;60;57-66.

4. Data Statistik Indonesia, Penduduk 60 tahun ke atas menurut kabupaten/kota dan keadaan kesehatan, Sulawesi Utara. Available from; http://datastatistikindonesia.com.

5. Departemen Kesehatan Republik Indonesia. Petunjuk Teknis Pengukuran Kebugaran Jasmani. Jakarta, 2005.

6. Betik A. Determinants of $\mathrm{VO}_{2}$ max decline with aging: an intergrated perspective. Appl Physiol Nutr Metab. 2008;33:130-40.

7. Perwati NM, Karmaya N, Sutjana D. Senam Tera Indonesia meningkatkan kebugaran janting paru lansia di panti Werda Wana Seraya Denpasar. Public Health and Preventive Medicine Archive. 2013;1(1).

8. Van Roei E, Delecluse C, Opdenacker J, de Bock $\mathrm{K}$, Kennis $\mathrm{E}$, Boen $\mathbf{F}$. 
Effectiveness of a lifestyle physical activity versus a structured exercise intervention in older adults. Journal of Aging and Physical Activity. 2010;18:335-52

9. Ulitandari A. Pengaruh latihan fisik terprogram terhadap perubahan nilai konsumsi oksigen maksimal $\left(\mathrm{VO}_{2} \max \right)$ pada siswi sekolah bola voli Tugu Muda Semarang usia 11-13 tahun [Skripsi]. Semarang: Fakultas Kedokteran Universitas Diponegoro; 2009. 